\title{
Manufacturing Scheduling Performance - A Case Study
}

\author{
Borut Buchmeister, Iztok Palcic \& Robert Ojstersek
}
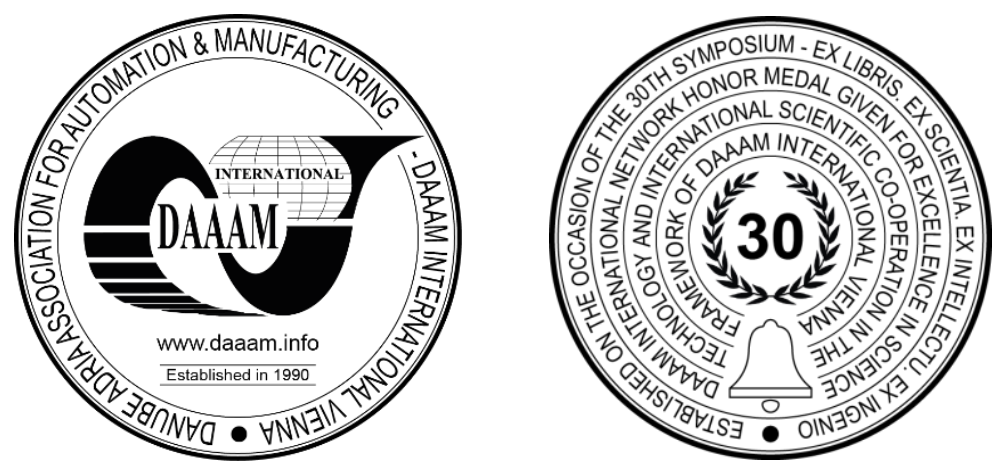

This Publication has to be referred as: Buchmeister, B[orut]; Palcic, I[ztok] \& Ojstersek, R[obert] (2019). Manufacturing Scheduling Performance - a Case Study, Proceedings of the 30th DAAAM International Symposium, pp.0020-0029, B. Katalinic (Ed.), Published by DAAAM International, ISBN 978-3-902734-22-8, ISSN 1726-9679, Vienna, Austria

DOI: $10.2507 / 30$ th.daaam.proceedings.003

\begin{abstract}
Scheduling as a research area is motivated by questions that arise in production planning and, generally, in all situations in which scarce resources have to be allocated to activities over time. One of the major reasons, why scheduling receives so much attention, is that information technology enables the shifting of a production strategy from push system to pull system. The purpose of implementing a pull system is to manufacture products based on actual demand and not on forecasts.

This paper compares three approaches for manufacturing scheduling, starting with traditional push approach (MRP) and continuing with Kanban (pull) and with Theory of Constraints - TOC (pull/push), regarding performance and throughput improvement. Kanban as well as TOC showed a stable and lower number of active tasks and shorter task completion time compared to traditional production scheduling, but on the account of lower resource efficiency.
\end{abstract}

Keywords: Scheduling; Push system; Pull system; Kanban; Theory of constraints.

\section{Introduction}

Companies are searching how to efficiently use their resources. Time is a limiting unrecoverable resource and we must schedule our tasks to utilise this limited resource in an optimum manner. Efficient use of time is namely one of the greatest indicators of competitiveness. In order to achieve that, they are heavily loading system's resources, so that the key resources are always busy. On the other hand, the system is strong as the weakest chain in a system. Therefore, the capacity or throughput of the system is limited by the weakest link, called capacity constrained resources (CCR) [1].

Clearly, having less work in the system will result in starvation of CCR and consequently also in reduced throughput of the system. On the other hand, due dates and quality requirements of customers are one of the major criteria to retain and build competitive advantage on markets. However, this is difficult to achieve, if the CCRs are overloaded with tasks. Therefore, the need for solution is identified that will schedule tasks throughout the system and will limit the number of active tasks and increase predictability and flow stability through it. 
Traditional, push-based approach is usually suggested for products with small demand uncertainty, as the forecast will provide a good indication of what to produce and keep in inventory, and also for products with high importance of economies of scale in reducing costs (Fig. 1). MRP approach is widely employed by most manufacturing companies, even though field applications point out some weaknesses, including ignored production capacity constraints and fixed leadtimes. The scheduling functions in a company rely on mathematical techniques and heuristic methods to allocate limited resources to the activities that have to be done. Beside classic dispatching rules to sequence the work waiting at workstations plenty of non-conventional methods (using artificial intelligence) are applied for optimization of scheduling problems, [2] to [7]. Objectives can take many different forms, such as minimizing the time to complete all activities, minimizing the number of activities that are completed after the committed due dates, and so on.

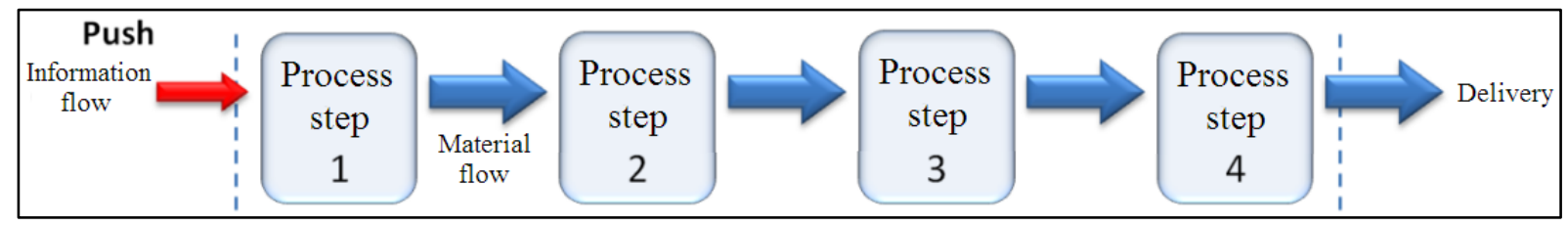

Fig. 1. Basic principles of push-based approach

Two advanced general approaches have been widely used in the past decades in manufacturing companies in order to improve throughput of the system, thus reducing number of active tasks in a system: Kanban [8] and Theory of Constraints (TOC) [9].

Kanban, translated signboard or billboard in Japanese, is a scheduling system to control number of active tasks in a system, developed by Taiichi Ohno, an industrial engineer at Toyota. Kanban became an effective tool to support running a production system as a whole, and a way to promote improvement. One key indicator of the success of production scheduling based on demand, pushing, is the ability of the demand-forecast to create such a push. Kanban, by contrast, is part of an approach where the pull comes from demand (Fig. 2). Re-supply or production is determined according to the actual demand of the customer. In contexts where supply time is lengthy and demand is difficult to forecast, often, the best one can do is to respond quickly to observed demand. This situation is exactly what a Kanban system accomplishes, in that it is used as a demand signal that immediately travels through the supply chain. Where the supply response is not quick enough to meet actual demand fluctuations, thereby causing potential lost sales, stock building may be deemed more appropriate, and is achieved by placing more Kanban in the system. Kanban approach can help operation managers to make efficacious decisions [10].

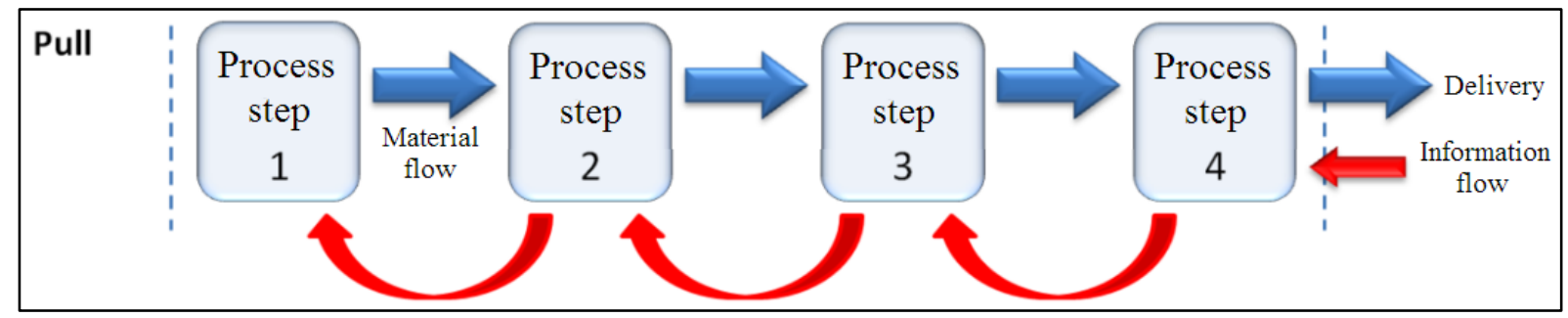

Fig. 2. Basic principles of pull-based approach

Second approach, introduced by Eliyahu M. Goldratt, is called Theory of Constraints (TOC) [11]. Despite its name it is not particularly theoretical. Rather, its tools and applications are designed to solve business problems in a practical and effective manner. The methodology assumes that every system or organization can be characterized as network of interdependent processes or elements. This means that systems are analogous to chains, or networks of chains. Like a chain, the system performance is limited by the weakest link - constraint. This means that no matter how much effort you put into improving the processes of a system, only the improvements to the weakest link will produce any detectable system improvement, [12] to [15]. TOC provides tools and applications that enable organizations to identify the constraints (or few of them), exploits them and subordinates others based on that decision in order to get the most out of the existing system or organization. To accomplish this, TOC shifts the focus of management from optimizing separate organizational units, functions and resources to increasing the flow of throughput generated by the entire system. TOC's key processes are focused on removing barriers that prevent each part from working together as an integrated whole. TOC becomes an important problem structuring and solving methodology, which changes the way of thinking of managers [16], [17], [18].

Additionally, the Drum-Buffer-Rope (DBR) [15], [19], [20] is powerful and robust TOC solution that is intended to manage the flow of work through a (development) process rather than managing the capacity of resources. It is designed 
to protect against general cause variation that cannot be removed from the system and some special cause variation. In the DBR literature, the focus is on the urgency of jobs and the same procedure is used both for backlog sequencing and dispatching. As basis for its work it uses first three steps of five focusing steps defined by TOC: identify the system constraint, decide how to exploit the system constraint and subordinate everything else to the above decisions. Basic principle of DBR is shown in Fig. 3.

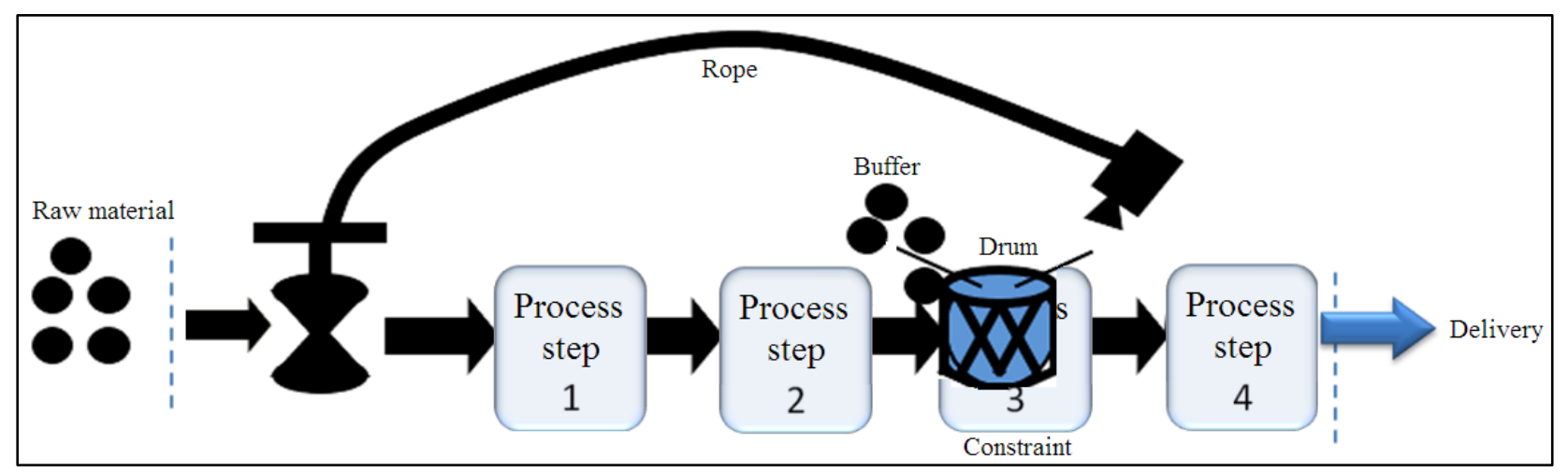

Fig. 3. Basic principles of Drum-Buffer-Rope (DBR)

A lot of researchers have simulated DBR systems, sometimes to estimate DBR's parameters, such as the time buffer, or to compare DBR's effectiveness with other systems. The analysis presented in this paper offers a simple methodology to help decide when to release additional work to the system. A discrete-event simulation model was developed to compare and evaluate traditional manufacturing scheduling approach with Kanban and TOC. The simulator has been written in C\# as a WPF program in Microsoft Visual Studio 2015.

Through the simulation, we want to answer the following questions:

1. What are the average task execution times (lead time) for traditional manufacturing (to be used as a baseline)?

2. How do the average task execution times for Kanban and for TOC compare to the average time for traditional manufacturing at the same process?

3. How does the average task execution time for TOC compare to the average time for Kanban at the same process?

4. Which methodology gives the best results considering average task execution time, standard deviation for task execution time, and lowest number of active tasks / inventory (Work-in-Progress - WIP level)?

\section{Simulation setup}

For simulation, we are using balanced dices (with 4, 6, 8, 12, 16 and 20 surfaces) distributed on workplaces. Each workplace has one operator and one machine, represented by the player and the dice (in each cycle player throws the dice ones and the value of the dice represents the production of that workplace for cycle). Workplaces are ordered in one linear sequence. At the Product Orders we have unlimited supply of tokens and for Finished Products we assume that they are all purchased directly from the end of the production line. Each workplace has a WIP storage, where finished (semi)products from the previous cycle are stored (Fig. 4).

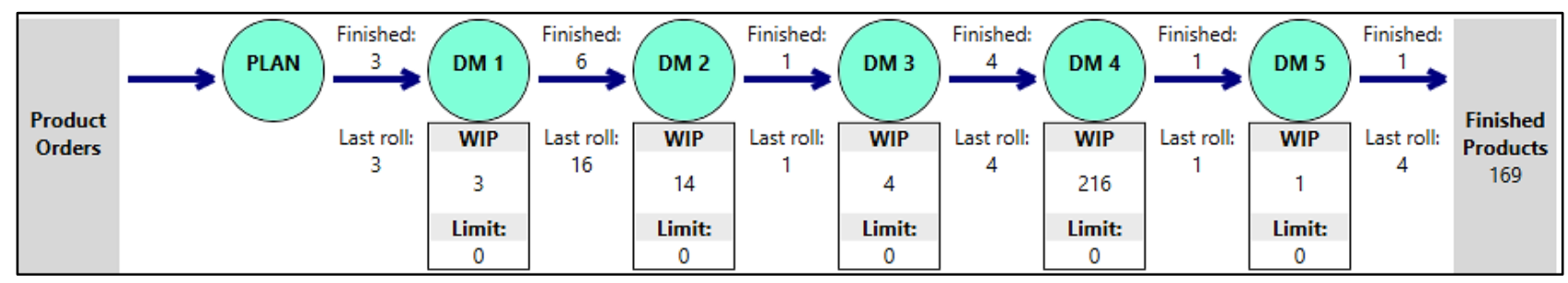

Fig. 4. Process setup in simulation (during sample simulation in the simulator)

Simulation model (for all cases) consists of 6 workplaces (Fig. 4) with balanced dice assigned as follows:

- PLAN - max. 8 products per cycle,

- DM1 - max. 20 semi-finished products per cycle,

- DM2 - max. 16 semi-finished products per cycle,

- DM3 - max. 12 semi-finished products per cycle, 
- DM4 - max. 4 semi-finished products per cycle,

- DM5 - max. 6 finished products per cycle.

Basic rules for the simulation:

- Each workplace has on unbalanced dice with different number of surfaces.

- One cycle is one dice roll at each workplace representing the productivity for one 8-hour shift.

- In each cycle, all workplaces perform the dice roll at the same time (since they are all working in the same 8-hour shift).

- First workplace (PLAN) plays the role of the gatekeeper and pulls the material from unlimited supply.

- All other workplaces pull needed material from the WIP of previous workplace (each operator can only take the maximum amount available at previous workplace WIP; if there is not enough available material in the WIP of previous workplace, the operator cannot wait for additional material from current simulation step).

- We start the simulation with zero material in each workplace WIP.

Other assumptions for the simulation:

- We have a simplified process (no lead time at the beginning of each cycle; at each workplace, we only have one machine, if we have more, they are represented with higher available maximum productivity and are considered as one, more productive, machine).

- No problems with workforce and logistics (no prioritizations of tasks; independent process - no artificial delays; all input materials are available on demand; no sick leaves of workers or downtimes of machines; customer buys all finished products immediately).

\subsection{Simulation setup for $M R P$}

Simulation setup for traditional (MRP) scheduling is set up with no constrains on WIP with maximum throughput based on dice roll in each cycle. Each simulation will run for 100 cycles with 20 replications.

\subsection{Simulation setup for Kanban production}

Simulation setup for Kanban production is set up with the constraint of 5 semi-finished products in WIP for each workplace (estimation based on trial runs). Each simulation will run for 100 cycles with 20 replications.

\subsection{Simulation setup for DBR (TOC) production}

Based on results of simulation for traditional production scheduling, it is established, that CCR is workplace DM4 and it plays the role of the Drum in simulation of this process. Buffer capacity is set to 15 semi-finished products based on trial runs. Each simulation will run for 100 cycles with 20 replications.

\section{Results and discussion}

In Table 1 the following parameters are displayed on the horizontal axis for each process, based on 20 simulations: Min. - minimal value among 20 performed simulations, Max. - maximum value among 20 performed simulations, Avg. - average value among 20 performed simulations. On vertical axis, the following parameter values are displayed: End WIP - WIP after the end of simulation, Finished products - quantity of finished products after 100 cycles of simulation, Production time, min. - minimum production time in 100 cycles of simulation, Production time, max. - maximum production time in 100 cycles of simulation, Production time, avg. - average production time for 100 cycles of simulation, Standard deviation - standard deviation of production time for 100 cycles of simulation.

\begin{tabular}{|l|c|c|c|c|c|c|c|c|c|}
\cline { 2 - 11 } \multicolumn{1}{c|}{} & \multicolumn{4}{c|}{ Mpproach } & \multicolumn{3}{c|}{ Kanban } & \multicolumn{3}{c|}{ DBR } \\
\cline { 2 - 11 } \multicolumn{1}{c|}{} & Min. & Max. & Avg. & Min. & \multicolumn{1}{c|}{ Max. } & Avg. & Min. & Max. & Avg. \\
\hline End WIP & 184 & 265 & $\mathbf{2 1 7 , 6}$ & 12 & 17 & $\mathbf{1 4}$ & 14 & 18 & $\mathbf{1 5 , 4}$ \\
\hline Finished products & 173 & 203 & $\mathbf{1 8 6 , 4}$ & 161 & 181 & $\mathbf{1 7 2 , 1}$ & 172 & 205 & $\mathbf{1 8 5 , 3}$ \\
\hline Production time, min. & 5 & 5 & $\mathbf{5}$ & 5 & 5 & $\mathbf{5}$ & 5 & 5 & $\mathbf{5}$ \\
\hline Production time, max. & 46 & 62 & $\mathbf{5 3 , 2}$ & 9 & 12 & $\mathbf{1 0 , 5}$ & 9 & 15 & $\mathbf{1 1 , 2}$ \\
\hline Production time, avg. & 25 & 35 & $\mathbf{2 9 , 1}$ & 7 & 8 & $\mathbf{7 , 2}$ & 6 & 8 & $\mathbf{7 , 1}$ \\
\hline Standard deviation & 11,77 & 17,88 & $\mathbf{1 3 , 9}$ & 0,76 & 1,54 & $\mathbf{1 , 2}$ & 0,91 & 1,71 & $\mathbf{1 , 2}$ \\
\hline
\end{tabular}

Table 1. Summary of 60 simulations 
Results by used approach are given below.

\subsection{Traditional (MRP) production scheduling}

Simulation of traditional production scheduling serves as a baseline for comparison with other approaches, for initial WIP restriction and for CCR identification.

\begin{tabular}{|c|c|c|c|c|c|c|}
\hline \multirow[b]{2}{*}{ Iteration } & \multirow[b]{2}{*}{ End WIP } & \multirow[b]{2}{*}{ Finished } & \multicolumn{4}{|c|}{ Duration } \\
\hline & & & Min. & Max. & Avg. & Std. dev. \\
\hline 1 & 205 & 176 & 5 & 50 & 30 & 13,36 \\
\hline 2 & 240 & 185 & 5 & 54 & 29 & 14,13 \\
\hline 3 & 192 & 195 & 5 & 48 & 27 & 12,73 \\
\hline 4 & 214 & 183 & 5 & 52 & 30 & 14,11 \\
\hline 5 & 248 & 186 & 5 & 60 & 35 & 14,19 \\
\hline 6 & 244 & 173 & 5 & 62 & 31 & 17,88 \\
\hline 7 & 219 & 193 & 5 & 52 & 31 & 13,99 \\
\hline 8 & 195 & 181 & 5 & 55 & 31 & 13,54 \\
\hline 9 & 220 & 189 & 5 & 53 & 27 & 14,34 \\
\hline 10 & 210 & 194 & 5 & 50 & 27 & 13,28 \\
\hline 11 & 184 & 181 & 5 & 47 & 25 & 12,64 \\
\hline 12 & 188 & 186 & 5 & 52 & 29 & 12,46 \\
\hline 13 & 189 & 187 & 5 & 46 & 28 & 11,77 \\
\hline 14 & 199 & 200 & 5 & 50 & 26 & 13,26 \\
\hline 15 & 220 & 186 & 5 & 56 & 32 & 15,87 \\
\hline 16 & 249 & 194 & 5 & 56 & 29 & 14,48 \\
\hline 17 & 265 & 173 & 5 & 56 & 30 & 14,13 \\
\hline 18 & 218 & 180 & 5 & 57 & 29 & 14,56 \\
\hline 19 & 255 & 182 & 5 & 57 & 29 & 14,77 \\
\hline 20 & 197 & 203 & 5 & 51 & 27 & 13,05 \\
\hline
\end{tabular}

Table 2. Traditional production scheduling simulations summary

Table 2 shows that average number of finished products in 100 iterations was 186,4. End WIP after 100 iterations is 217,6 , which represents $177 \%$ of finished products. Fastest production time was 5 cycles while slowest was on average 53,2 cycles resulting in production time average of 29,1 cycle with average standard deviation of 13,9 cycles. Iteration no. 7 is closest to these averages and is used for further more detailed analysis.

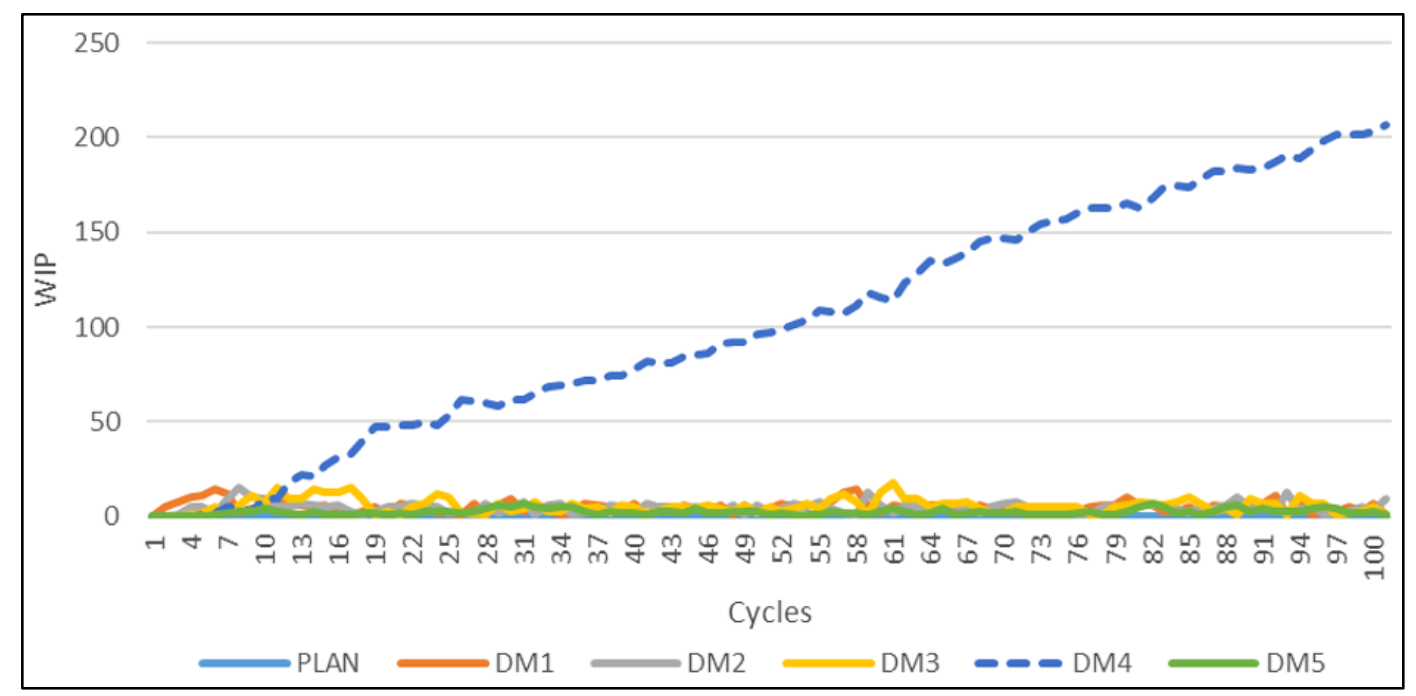

Fig. 5. Simulation 7 - current cycle WIP at workplaces

Fig. 5 reveals that WIP is relatively stable around 5 on all workplaces, except before workplace DM4, where it linearly grows. This means, that our CCR is workplace DM4. 


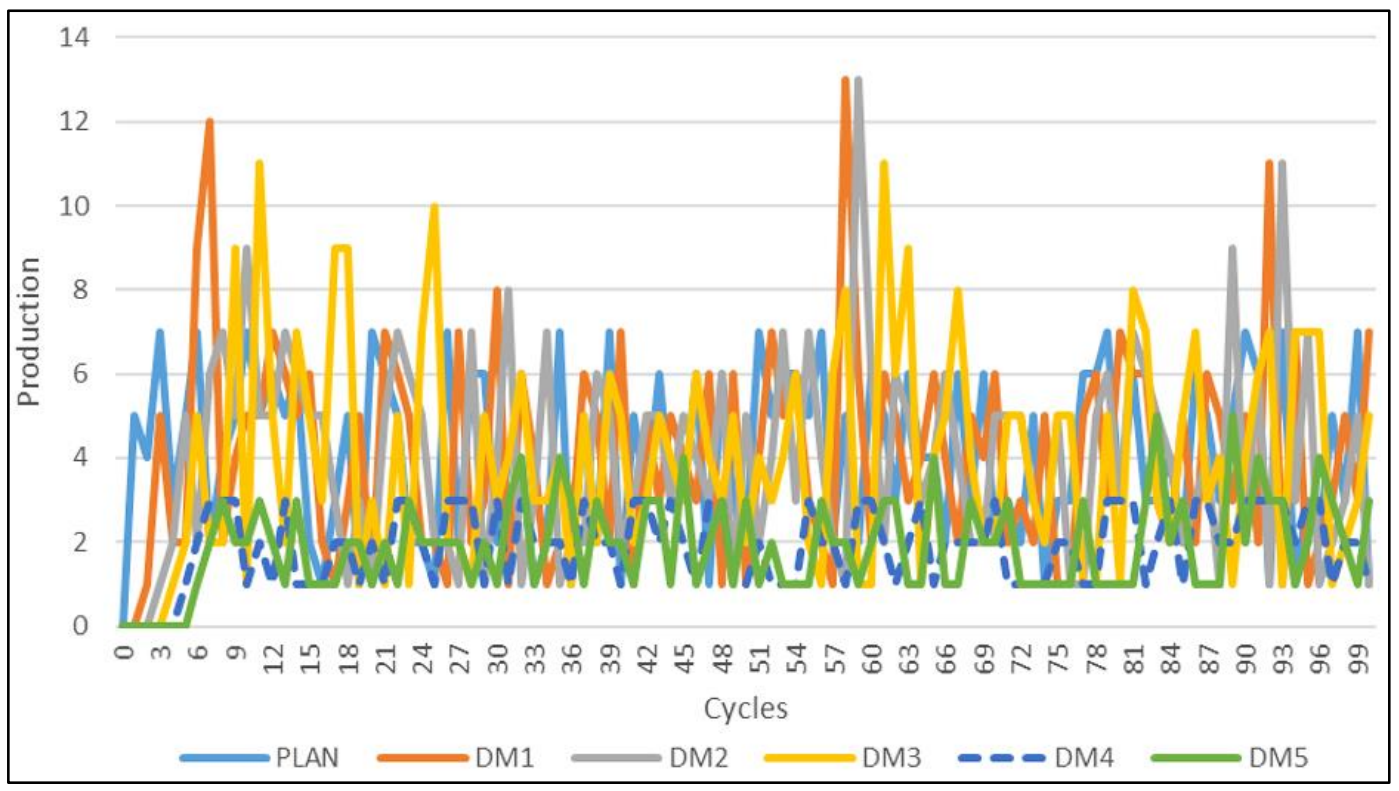

Fig. 6. Simulation 7 - production at workplaces

Fig. 6 displays production (flow) for each workplace by iterations. There are no production outages (due to lack of material at previous workplace WIP) detected except at the beginning of production (due to lead time). Chart also reveals that DM5 is not working at full capacity because of the limited supply from the DM4. Production on other workplaces is within expected statistical variance.

\subsection{Kanban production scheduling}

Based on the results for MRP production scheduling, where WIP was around 5 on almost all workplaces except CCR, this number was used as WIP constraint for each workplace WIP.

\begin{tabular}{|c|c|c|c|c|c|c|}
\hline & & & \multicolumn{5}{|c|}{ Duration } \\
\cline { 4 - 7 } Iteration & WIP & Finished & Min. & Max. & Avg. & Std. dev. \\
\hline 1 & 13 & 173 & 5 & 11 & 7 & 1,53 \\
\hline 2 & 16 & 172 & 5 & 10 & 7 & 1 \\
\hline 3 & 14 & 166 & 5 & 10 & 8 & 0,99 \\
\hline 4 & 13 & 176 & 5 & 10 & 7 & 1,25 \\
\hline 5 & 12 & 173 & 5 & 11 & 7 & 1,28 \\
\hline 6 & 14 & 171 & 5 & 11 & 7 & 1,08 \\
\hline 7 & 15 & 177 & 5 & 9 & 7 & 0,76 \\
\hline 8 & 15 & 173 & 5 & 10 & 7 & 0,98 \\
\hline 9 & 12 & 177 & 5 & 9 & 7 & 1,03 \\
\hline 10 & 17 & 165 & 5 & 11 & 7 & 1,4 \\
\hline 11 & 13 & 177 & 5 & 10 & 7 & 1,03 \\
\hline 12 & 14 & 181 & 5 & 10 & 7 & 0,9 \\
\hline 13 & 16 & 171 & 5 & 11 & 7 & 1,32 \\
\hline 14 & 14 & 177 & 5 & 10 & 7 & 1,22 \\
\hline 15 & 13 & 166 & 5 & 10 & 8 & 1,14 \\
\hline $\mathbf{1 6}$ & $\mathbf{1 4}$ & $\mathbf{1 7 2}$ & $\mathbf{5}$ & $\mathbf{1 0}$ & $\mathbf{7}$ & $\mathbf{1 , 2 1}$ \\
\hline 17 & 13 & 176 & 5 & 11 & 7 & 1,16 \\
\hline 18 & 12 & 176 & 5 & 11 & 7 & 1,54 \\
\hline 19 & 15 & 161 & 5 & 12 & 8 & 1,47 \\
\hline 20 & 15 & 162 & 5 & 12 & 8 & 1,15 \\
\hline
\end{tabular}

Table 3. Kanban simulations summary

Table 3 shows that the average number of finished products in 100 iterations was 172,1 (which represents $92 \%$ of production with MRP production scheduling). Average end WIP after 100 iterations is 14 , which represents $8 \%$ of 
finished products. End WIP with Kanban represents only $3 \%$ of end WIP with MRP production scheduling. Fastest production time was 5 cycles while slowest was on average 10,5 cycles resulting in production time average of 7,2 cycle with average standard deviation of 1,2 cycles. Iteration no. 16 is closest to these averages and is used for further more detailed analysis.

Fig. 7 reveals that WIP is relatively stable at all workplaces, except at workplace DM5, where they are the lowest due to limited supply from DM4 which was already identified as CCR.

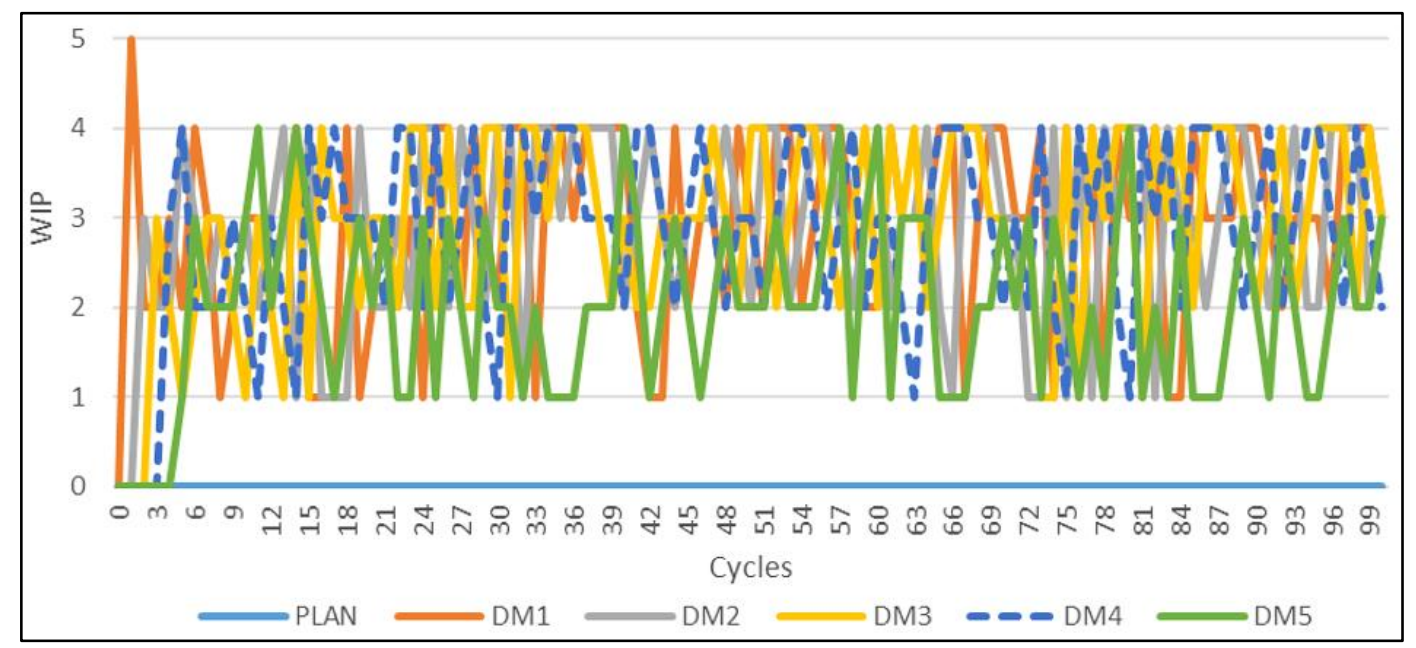

Fig. 7. Simulation 16 - current cycle WIP at workplaces

Fig. 8 displays production (flow) for each workplace by iterations. There are no production outages (due to lack of material at previous workplace WIP) detected except at the beginning of production (due to lead time). Chart also reveals that production at all workplaces is relatively synchronized.

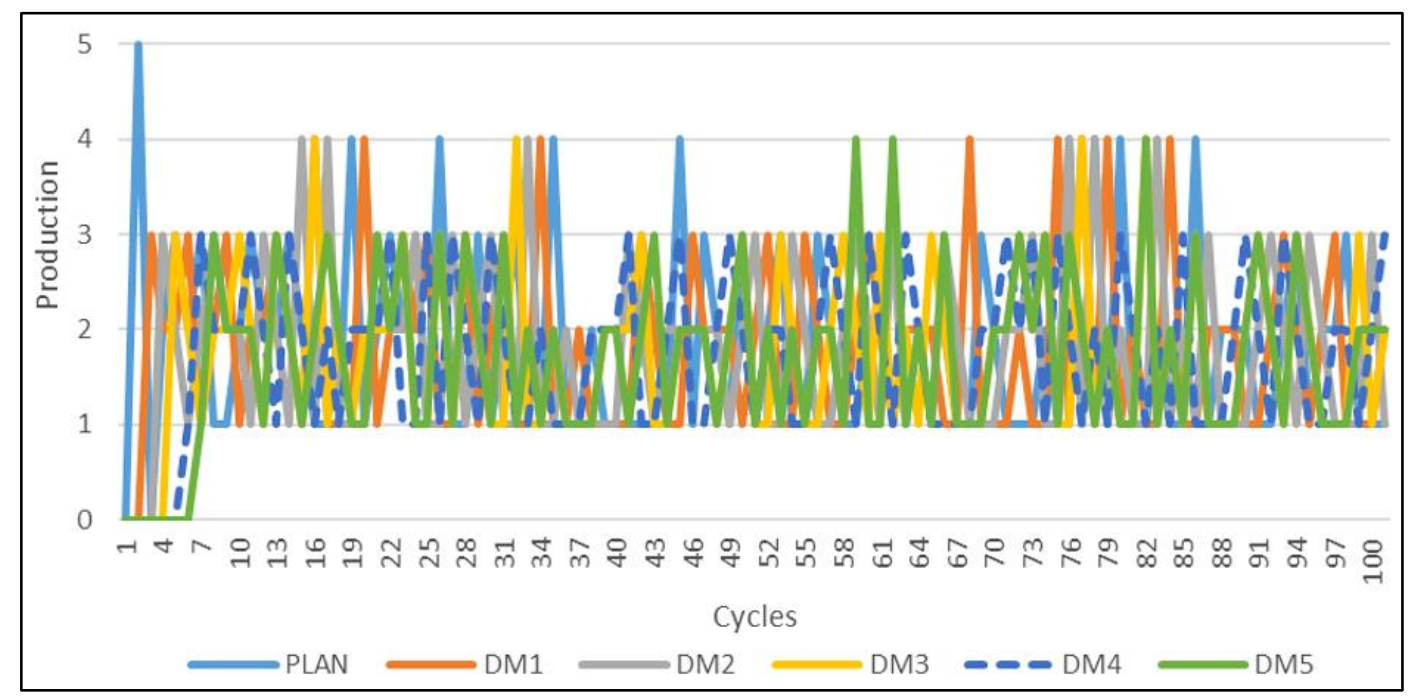

Fig. 8. Simulation 16 - production at workplaces

\subsection{TOC-DBR production scheduling}

Based on results for MRP production scheduling, where WIP at all workplaces before CCR was around 5, this value was used for buffer size estimation. Since there are three workplaces before CCR/DM4 (DM1, DM2 and DM3 - PLAN is in our process only gatekeeper), size of the buffer was set to 15.

Table 4 shows that average number of finished products in 100 iterations was 185,3 (which represents $99 \%$ of production with MRP production scheduling). Average end WIP after 100 iterations is 15,4, which represents 8,2\% of finished products. Fastest production time was 5 cycles while slowest was on average 11,2 cycles resulting in production time average of 7,1 cycle with average standard deviation of 1,2 cycles. Iteration no. 18 is closest to these averages and is used for further more detailed analysis. 


\begin{tabular}{|c|c|c|c|c|c|c|}
\hline \multirow[b]{2}{*}{ Iteration } & \multirow[b]{2}{*}{ WIP } & \multirow[b]{2}{*}{ Finished } & \multicolumn{4}{|c|}{ Duration } \\
\hline & & & Min. & Max. & Avg. & Std. dev. \\
\hline 1 & 15 & 175 & 5 & 11 & 8 & 1,31 \\
\hline 2 & 16 & 178 & 5 & 11 & 7 & 1,44 \\
\hline 3 & 15 & 194 & 5 & 10 & 7 & 1,05 \\
\hline 4 & 15 & 179 & 5 & 12 & 7 & 1,14 \\
\hline 5 & 15 & 199 & 5 & 11 & 7 & 0,99 \\
\hline 6 & 15 & 172 & 5 & 15 & 8 & 1,21 \\
\hline 7 & 15 & 181 & 5 & 11 & 6 & 1,21 \\
\hline 8 & 17 & 189 & 5 & 10 & 7 & 1 \\
\hline 9 & 14 & 189 & 5 & 11 & 7 & 1,26 \\
\hline 10 & 15 & 184 & 5 & 12 & 7 & 1,28 \\
\hline 11 & 16 & 183 & 5 & 13 & 7 & 1,67 \\
\hline 12 & 16 & 187 & 5 & 11 & 7 & 1,14 \\
\hline 13 & 16 & 185 & 5 & 11 & 7 & 1,37 \\
\hline 14 & 14 & 205 & 5 & 9 & 6 & 0,91 \\
\hline 15 & 15 & 174 & 5 & 11 & 8 & 1,23 \\
\hline 16 & 18 & 177 & 5 & 12 & 7 & 1,71 \\
\hline 17 & 15 & 188 & 5 & 10 & 7 & 0,93 \\
\hline 18 & 16 & 184 & 5 & 11 & 7 & 1,27 \\
\hline 19 & 14 & 197 & 5 & 10 & 7 & 1,15 \\
\hline 20 & 15 & 185 & 5 & 11 & 7 & 1,3 \\
\hline
\end{tabular}

Table 4. DBR simulations summary

Fig. 9 reveals that WIP is relatively stable at all workplaces except WIP before DM4 (already identified as CCR) which varies between 3 and 10 .

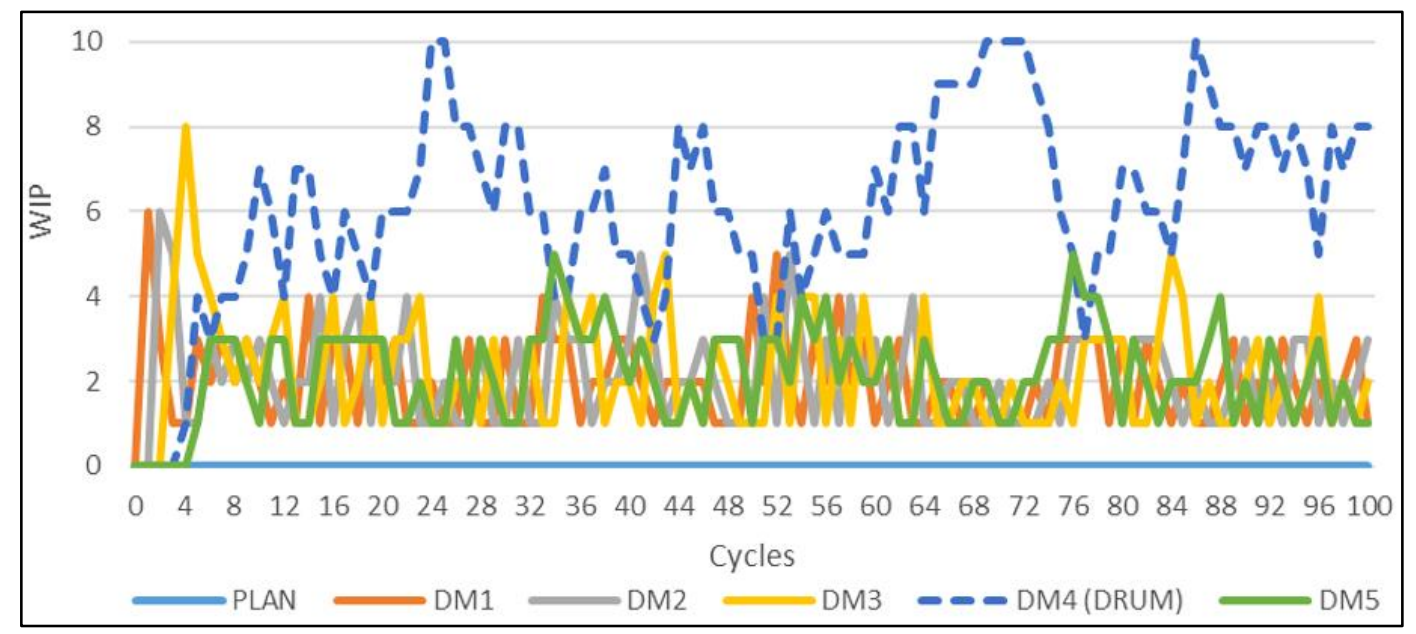

Fig. 9. Simulation 18 - WIP before each workplace

Fig. 10 displays production (flow) for each workplace by iterations. There are no production outages (due to lack of material at previous workplace WIP) detected, except on the beginning of production (due to lead time). Chart also reveals that production at all workplaces is synchronized resulting in smooth production flow.

With the combination of average production time (in cycles) and average standard deviations of production times the following production times are predicted:

- MRP production scheduling has average production time of 29,1 cycles and average standard deviation of 13,9 cycles, so we can expect production times between 15 and 43 cycles.

- Kanban has average production time of 7,2 cycles and average standard deviation of 1,2 cycle, so we can expect production times between 6 and 8 cycles.

- DBR has average production time of 7,1 cycles and average standard deviation of 1,2 cycle, so we can expect production times between 6 and 8 cycles. 


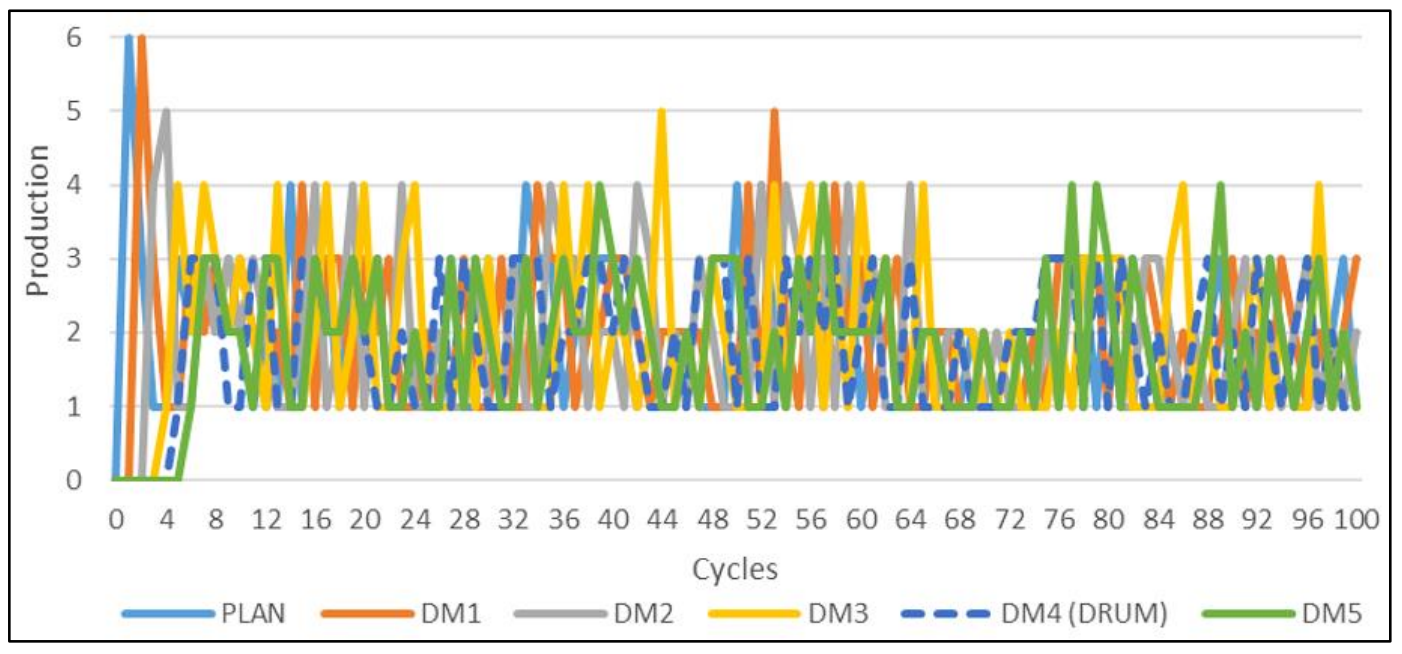

Fig. 10. Simulation 18 - production at workplaces

\section{Conclusion}

Many manufacturing companies are now critically evaluating their processes to determine their effectiveness in bringing maximum value to customers [21]. They strive to include methods that greatly minimize lead time, reduce costs, and improve quality. A lean pull system has the purpose of creating a workflow where work is pulled only if there is a demand for it. Companies can focus on eliminating waste activities in the production process. They are able to optimize their resources and cost efficiency and reduce the possibility of overstocking.

In this paper it has been analysed and formalized some findings using simulator for implementation of Kanban and Theory of Constraints tools on sample manufacturing line. Analyses showed that resource productivity is at its highest with traditional production scheduling, but on the account of high inventory (number of active tasks) at the Capacity Constrained Resource (CCR) and by far the longest time for task completion (lead time). Kanban as well as TOC showed shorter task completion time compared to traditional production scheduling, but on the account of lower resource efficiency.

The key finding of this article is that control over the number of active tasks in a system is more important than continuous full utilization of all resources (efficiency) and significantly impacts production lead time through lower number of active tasks (effectiveness).

Our future research activities in scheduling field will be oriented in development of balanced multi-criteria optimization using artificial intelligence approaches.

\section{Acknowledgment}

The authors acknowledge the financial support from the Slovenian Research Agency (research core funding No. P20190).

\section{References}

[1] Goldratt, E. M. (2003). Production the TOC Way with Simulator, The North River Press Publishing Corporation, ISBN 978-0884271758, Great Barrington

[2] Buchmeister, B. \& Palcic, I. (2015). Advanced job shop scheduling methods, In: DAAAM International Scientific Book 2015, Katalinic, B. (Ed.), pp. 1-16, DAAAM International, ISBN 978-3-902734-05-1, ISSN 1726-9687, Vienna

[3] Singh, A. (2015). Multicriteria Dynamic Scheduling by TOPSIS and Goal Programming, Proceedings of the $26^{\text {th }}$ DAAAM International Symposium, Zadar, ISSN 1726-9679, ISBN 978-3-902734-07-5, Katalinic, B. (Ed.), pp. 426434, DAAAM International, Vienna, DOI:10.2507/26th.daaam.proceedings.057

[4] Rossi, T.; Pozzi, R.; Pero, M. \& Cigolini, R. (2017). Improving production planning through finite-capacity MRP. International Journal of Production Research, Vol. 55, No. 2, pp. 377-391, ISSN 0020-7543, DOI:10.1080/00207543.2016.1177235

[5] Pooya, A. \& Pakdaman, M. (2019). Optimal control model for finite capacity continuous MRP with deteriorating items. Journal of Intelligent Manufacturing, Vol. 30, No. 5, pp. 2203-2215, ISSN 0956-5515, DOI:10.1007/s10845017-1383-6 
[6] Majazi Dalfard, V. \& Ranjbar, V. (2012). Multi-projects scheduling with resource constraints \& priority rules by the use of simulated annealing algorithm. Technical Gazette, Vol. 19, No. 3, pp. 493-499, ISSN 1330-3651

[7] Tang, M.; Gong, D.; Liu, S. \& Zhang, H. (2016). Applying multi-phase particle swarm optimization to solve bulk cargo port scheduling problem. Advances in Production Engineering \& Management, Vol. 11, No. 4, pp. 299-310, ISSN 1854-6250, DOI:10.14743/apem2016.4.228

[8] Lu, D. J. (1989). Kanban Just-in Time at Toyota: Management Begins at the Workplace (Revised ed.), Productivity Press, ISBN 978-0915299089, Portland

[9] Goldratt, E. M. \& Cox, J. (2004). The Goal: A Process of Ongoing Improvement, North River Press, ISBN 9780884271789, Great Barrington

[10] Krishnaiyer, K. \& Chen, F. F. (2017). A cloud-based Kanban decision support system for resource scheduling \& management, $27^{\text {th }}$ International Conference on Flexible Automation and Intelligent Manufacturing (FAIM), Modena, Pellicciari, M. \& Peruzzini, M. (Eds.), Procedia Manufacturing, Vol. 11, pp. 1489-1494, ISSN 2351-9789, DOI:10.1016/j.promfg.2017.07.280

[11] Goldratt, E. M. (1999). Theory of Constraints, North River Press Publishing Corporation, ISBN 978-0884271666, Great Barrington

[12] Simsit, Z. T.; Gunay, N. S. \& Vayvay, O. (2014). Theory of constraints: a literature review, Proceedings of the $10^{\text {th }}$ International Strategic Management Conference, Rome, Ozsahin, M. (Ed.), Procedia - Social and Behavioral Sciences, Vol. 150, pp. 930-936, ISSN 1877-0428, DOI:10.1016/j.sbspro.2014.09.104

[13] Naor, M.; Bernardes, E. S. \& Coman, A. (2013). Theory of constraints: is it a theory and a good one?. International Journal of Production Research, Vol. 51, No. 2, pp. 542-554, ISSN 0020-7543, DOI:10.1080/00207543.2011.654137

[14] Golmohammadi, D. (2015). A study of scheduling under the theory of constraints. International Journal of Production Economics, Vol. 165, pp. 38-50, ISSN 0925-5273, DOI:10.1016/j.ijpe.2015.03.015

[15] Zhang, X. M. \& Du, Y. L. (2015). Research of production scheduling based on theory of constraints, Proceedings of the 2015 International Conference on Electrical, Automation and Mechanical Engineering, Phuket, ISBN 97894-62520-71-4, Chan, K. \& Yeh, J. (Eds.), pp. 142-145, Atlantis Press, Paris, DOI:10.2991/eame-15.2015.39

[16] Golmohammadi, D. \& Mansouri, S. A. (2015). Complexity and workload considerations in product mix decisions under the theory of constraints. Naval Research Logistics, Vol. 62, No. 5, pp. 357-369, ISSN 1520-6750, DOI:10.1002/nav.21632

[17] Zhong, Q.; Yang, H. \& Tang, T. (2018). Optimization algorithm simulation for dual-resource constrained job-shop scheduling. International Journal of Simulation Modelling, Vol. 17, No. 1, pp. 147-158, ISSN 1726-4529, DOI:10.2507/IJSIMM17(1)CO2

[18] Wang, J.-Q.; Zhang, Z.-T.; Chen, J.; Guo, Y.-Z.; Wang, S.; Sun, S.-D.; Qu, T. \& Huang, G. Q. (2014). The TOCbased algorithm for solving multiple constraint resources: a re-examination. IEEE Transactions on Engineering Management, Vol. 61, No. 1, pp. 138-146, ISSN 0018-9391, DOI:10.1109/TEM.2013.2264830

[19] Thurer, M. \& Stevenson, M. (2018). On the beat of the drum: improving the flow shop performance of the DrumBuffer-Rope scheduling mechanism. International Journal of Production Research, Vol. 56, No. 9, pp. 3294-3305, ISSN 0020-7543, DOI:10.1080/00207543.2017.1401245

[20] Chakravorty, S. S. \& Hales, D. N. (2016). Improving labour relations performance using a Simplified Drum Buffer Rope (S-DBR) technique. Production Planning \& Control, Vol. 27, No. 2, pp. 102-113, ISSN 0953-7287, DOI:10.1080/09537287.2015.1079744

[21] Duplakova, D.; Teliskova, M.; Duplak, J.; Torok, J.; Hatala, M.; Steranka, J. \& Radchenko, S. (2018). Determination of optimal production process using scheduling and simulation software. International Journal of Simulation Modelling, Vol. 17, No. 4, pp. 609-622, DOI:10.2507/IJSIMM17(4)447 